\title{
Prevalence rates of Trichogramma evanescens (Westwood) in Ostrinia nubilalis (Hübner) population in the south of russia in 2013-2018
}

\author{
Inna Grushevaya* \\ All-Russian Institute of Plant Protection, Podbelskogo 3, 196608, St. Petersburg, Pushkin, Russia
}

\begin{abstract}
The European corn borer Ostrinia nubilalis (Hübner) is a dangerous corn pest - a convenient object for studying population dynamics and assessing various pest mortality factors. The mortality of European corn borer's eggs by the natural parasite population Trichogramma evanescens (Westwood) was estimated in 2013-2018 in the Gulkevichsky district of the Krasnodar Territory. Two generations of the European corn borer are developing in the Krasnodar Territory. Often pest's first generation of is not infected with the parasite. When monitoring the abundance of the second generation, even in years with a low abundance of the European corn borer, infected phytophage eggs are found in the crops of grain corn. Infection of eggs of the second-generation European corn borer in 2013-2018 ranged from 0.26 to $69.55 \mathrm{eggs} / \mathrm{m}^{2}$, with an average of $37.53 \mathrm{eggs} / \mathrm{m}^{2}$.
\end{abstract}

\section{Introduction}

The European corn borer Ostrinia nubilalis (Hübner) is a dangerous corn pest - a convenient object for studying population dynamics. The life cycle of the phytophage is realized within the rotation, the abundance and mortality at all stages of the development of generation from abiotic and biotic factors is easy to take into account [1]. Parasites of the genus Trichogramma are used as biological agents mainly against $O$. nubilalis in crops of grain, sweet and seed maize [2]. For commercial use of the parasite, information is needed on the density and dynamics of the natural population of the parasite in various crops of maize. Two full generations of the $O$. nubilalis develop annually in the Krasnodar Territory. Monitoring of abundance dynamics and analysis of pest survival tables revealed that in 2003 in the Krasnodar Territory the maximum pest mortality rate of the second generation was caused by the natural population of $T$. evanescens $[3,4]$. The purpose of the study is to evaluate the prevalence rates of the natural population of the oviphage Trichogramma in a local ECB population in 20132018. 


\section{Materials and Methods}

Monitoring the dynamics of the pest's abundance was performed in the Gulkevichsky district of the Krasnodar Territory in 2013-2018. Field work was carried out in stains of maize grown for grain within the crop rotation of the Kuban experimental station VIR and NPO KOS-MAIS. The densities of ECB eggs laid on corn and their infestation with a parasite were evaluated at stationary sites of 10 plants each (the first and last plants on the site were marked with paper labels); in this case, the total density of eggs laid over the entire period of egg laying was characterized by the sum of the estimates obtained during periodic (after 4-5 days) counts. The total number of eggs in the clusters, as well as the number of eggs from which the lepidopteran larvae emerged and those infected by the oviphage were counted using a manual magnifier. The number of sites for each account was 10-50 [5].

\section{Results and Discussion}

During the study period, both the number of the ECB and the infection of the phytophage eggs with the parasite $T$. evanescens were different over years and generations. The density of the number of corn borer varied greatly (the first generation - from 2.9 to $30.6 \mathrm{pcs} / \mathrm{m}^{2}$ of maize, the second generation - from 5.1 to $148.6 \mathrm{pcs} / \mathrm{m}^{2}$ ). The levels of parasite infection of the phytophage eggs of the first and second generations were different. Trichogramma infestation of the first-generation phytophage eggs was not intensive; it was observed only in twice within the observation timeframe. In 2013, the pest population density was $0.66 \mathrm{eggs} / \mathrm{m}^{2}$ and 0.31 eggs $/ \mathrm{m}^{2}$ were parasitized, corresponding to $47.37 \%$. In 2017 , the pest density was $4.76 \mathrm{eggs} / \mathrm{m}^{2}$, and $0.58 \mathrm{eggs} / \mathrm{m}^{2}$, were attacked by Trichogramma, i.e. $12.2 \%$.

In the second generation of the ECB, the density of the pest and its infestation with the parasite have been substantially increasing. Infection of eggs of the corn borer's secondgeneration in 2013-2018 ranged from 0.26 to $69.55 \mathrm{eggs} / \mathrm{m}^{2}$, with an average value of 37.53 eggs $/ \mathrm{m}^{2}$ The lowest oviphage prevalence rate $(2.77 \%)$ was observed in 2014 and the highest rate of parasitism $(70.86 \%)$ was in 2018 (Table 1$)$.

Table 1. The level of infection of eggs of the Ostrinia nubilalis of the 2 nd generation with the parasite Trichogramma evanescens in 2013-2018

\begin{tabular}{|c|c|c|c|}
\hline \multirow{2}{*}{ Year } & \multicolumn{2}{|c|}{ Number of } & \multirow{2}{*}{$\begin{array}{c}\text { Rate of egg } \\
\text { parasitism, \% }\end{array}$} \\
\cline { 2 - 4 } & eggs per $\mathrm{m}^{2}$ & eggs with Trichogramma per $\mathrm{m}^{2}$ & 52.81 \\
\hline 2013 & $4.81 \pm 0.96$ & $2.54 \pm 0.28$ & 2.78 \\
\hline 2014 & $9.37 \pm 0.77$ & $0.26 \pm 0.11$ & 38.48 \\
\hline 2015 & $117.11 \pm 15.77$ & $45.06 \pm 7.35$ & 43.99 \\
\hline 2016 & $133.98 \pm 15.68$ & $58.95 \pm 58.95$ & 48.20 \\
\hline 2017 & $144.3 \pm 20.54$ & $69.55 \pm 9.93$ & 70.86 \\
\hline 2018 & $68.88 \pm 4.14$ & $48.81 \pm 2.05$ & \\
\hline
\end{tabular}

As it can be seen, infestation rates of the corn borer's eggs of the first and second generations with the natural population of T. evanescens in 2013-2018 varied from year to year and from generation to generation. During periods of development of the first generation, when ECB density is low, the phytophage is rarely attacked, but with the advance of the second generation, the parasite is detected annually. 
The corn borer causes the greatest harm when the first generation feed by corn for various household purposes. During this period, the mortality of the pest from the natural population of the parasite is low. Whereas, during the growth of the phytophage population, the mortality of the ECB from the natural population of the Trichogramma is high. So, for example, in the south-west of Slovakia a rather high mortality of corn borer's eggs from the natural population of the Trichogramma was observed during abundance monitoring in 1993-1996. Infected masonry of corn moth eggs was not detected annually, but on separate counting days, in the presence of a parasite on corn crops egg mortality reached $100 \%$ [6]. The parasite was detected annually in sweet corn crops in Serbia, and the infection rate of second-generation corn moth eggs varied in 2004-2007 from 9.31 to $73.58 \%$ [7]. Data on monitoring the number of the ECB and pest egg mortality from the Trichogramma can be used to organize biological and integrated plant protection to determine the effective time for release of the parasite. To clarify the data, further monitoring of the corn borer in the Krasnodar Territory is required in order to clarify the timing and degree of infection of the phytophage on corn for various purposes (food, grain, silage).

\section{References}

1. A.N. Frolov, Plant Protection News [Vestnik zashchity rasteniy] 3(101), 4-33 (2019) http://doi.org/10.31993/2308-6459-2019-3(101)-4-33

2. S.A. Hassan. In: Trichogramma News, 6, 13-14 (1992)

3. A.N. Frolov, Plant Protection News [Vestnik zashchity rasteniy] 2, 37-47 (2004)

4. D.A. Serapionov, A. N. Frolov. Plant Protection and Quarantine [Zashcita i Karantin rasteniy] 2, 63-64 (2008)

5. A.N. Frolov, J.M. Malysh Plant Protection News [Vestnik zashchity rasteniy] 1, 42-55 (2004)

6. L. Cagan, J. Tancik, S. Hassan. J. Appl. Entomol. 122, 315-318 (1998) https://doi.org/10.1111/j.1439-0418.1998.tb01504.x

7. J. Tancik. Plant Protect. Sci., 53, 50-54 (2017) http://doi:10.17221/12/2016-PPS 